OPEN ACCESS

Edited by: Shervin Assari, University of Michigan, USA

Reviewed by: Masoumeh Dejman, Johns Hopkins School of

Public Heath, USA;

University of Social Welfare and Rehabilitation Sciences, Iran Ehsan Moazen Zadeh, Tehran Psychiatric Institute, Iran

*Correspondence: Jérôme Favrod j.favrod@ecolelasource.ch

Specialty section: This article was submitted to Public Mental Health, a section of the journal Frontiers in Psychiatry

Received: 24 November 2015 Accepted: 25 January 2016 Published: 17 February 2016

Citation: Nguyen A, Frobert L, McCluskey I, Golay P, Bonsack C and Favrod J (2016) Development of the Positive Emotions Program for Schizophrenia: An Intervention to Improve Pleasure and Motivation in Schizophrenia.

Front. Psychiatry 7:13 doi: 10.3389/fpsyt.2016.00013

\section{Development of the Positive Emotions Program for Schizophrenia: An Intervention to Improve Pleasure and Motivation in Schizophrenia}

\author{
Alexandra Nguyen ${ }^{1}$, Laurent Frobert ${ }^{1}$, lannis McCluskey ${ }^{1,2}$, Philippe Golay ${ }^{2}$, \\ Charles Bonsack ${ }^{2}$ and Jérôme Favrod ${ }^{1,2 *}$
}

'School of Nursing Science La Source, University of Applied Sciences and Arts of Western Switzerland, Lausanne, Switzerland, ${ }^{2}$ Social Psychiatry Section, Community Psychiatry Service, Department of Psychiatry, University Hospital Center, Lausanne, Switzerland

Objectives: The efficacy of drug-based treatments and psychological interventions on the primary negative symptoms of schizophrenia remains limited. Recent literature has distinguished negative symptoms associated with a diminished capacity to experience, from those associated with a limited capacity for expression. The positive emotions program for schizophrenia (PEPS) is a new method that specifically aims to reduce the syndrome of a diminished capacity to experience.

Methods: The intervention's vital ingredients were identified through a literature review of emotion in schizophrenia and positive psychology. The program has been beta-tested on various groups of health-care professionals.

Results: A detailed description of the final version of PEPS is presented here. The French version of the program is freely downloadable.

Conclusion: PEPS is a specific, short, easy to use, group-based intervention to improve pleasure, and motivation in schizophrenia. It was built considering a recovery-oriented approach to schizophrenia.

Keywords: schizophrenia, anhedonia, apathy, pleasure, motivation, psychosocial interventions

\section{INTRODUCTION}

Negative symptoms have long been recognized as a central feature of the phenomenology of schizophrenia, dating back to early descriptions by Kraepelin and Bleuler (1). They negatively affect patients' longitudinal social, occupational, and functional outcomes, as well their longterm recovery (2-5). Whereas positive symptoms (hallucinations, delusions) reflect an excess or distortion of normal functions, and negative symptoms (blunted affect, alogia, apathy-avolition, anhedonia, inattentiveness) represent the absence or reduction of normal emotions and behaviors. Negative symptoms are classified as primary or secondary. Primary negative symptoms comprise the core features intrinsic to schizophrenia itself. Secondary negative symptoms are transient; 
they are attributable and temporally related to the effects of such factors as unrelieved positive symptoms, depression, the adverse effects of antipsychotic drugs (akinesia), or the social isolation imposed by the stigma of schizophrenia. Primary and secondary negative symptoms may be similar in clinical expression, despite their contrasting etiologies (6). Often, secondary negative symptoms diminish with the resolution of their causative factors.

\section{Limitations of Current Techniques}

The efficacy of drug-based treatments and psychological interventions on primary negative symptoms remains limited, however (7-9). Fusar-Poli et al. (9), in their meta-analysis of 6,503 patients in the treatment arm and 5,815 patients in the placebo arm, showed that most treatments reduced negative symptoms at follow-up relative to placebo: second-generation antipsychotics, antidepressants, combinations of pharmacological agents, glutamatergic medications, and psychological interventions. However, none of the treatments used reached the threshold for clinically significant improvement as measured by clinicians using the Clinical Global Impression Severity Scale. The mean percentage change in treatment groups was $16.1 \%$, whereas the control group changed by an average $7.9 \%$. Improvements by treatment group, compared with the control group, varied between $4.8 \%$ for first-generation antipsychotics and $12.7 \%$ for psychological treatments. There is a clear clinical need for developing treatments for negative symptoms. The lack of clinically meaningful efficacy of drug or psychological treatments is in line with clinicians' practical experiences $(7,9)$. The existing psychological treatments have limitations (10). Family interventions to reduce negative symptoms appear promising when combined with other interventions. However, patients who have family members willing to be involved in treatment may merely represent a subgroup of people with schizophrenia. Furthermore, families who are more willing to participate in psychosocial interventions may provide patient's with greater support anyway and thus may not represent the broader population. Psychosocial interventions, such as cognitive behavior therapy (CBT), social skills training (SST), mindfulness-based intervention (MBI), family therapy (FT), or cognitive remediation (CR), combined with SST require highly trained therapists. The vast majority of studies were not specifically designed to target negative symptoms, and most assessed negative symptoms overall, without looking for the specific effects of the intervention. Several interventions were provided over long durations, requiring a great investment in time by the patients. For example, combining CR with SST may be useful for reducing negative symptoms, particularly social withdrawal, affective flattening, and motor retardation $(11,12)$, or a global score of negative symptoms (13). These interventions required $32-100 \mathrm{~h}$ of training. One 3-year study (14) indicated that improvements in negative symptoms did not occur until the second and third years of therapy. However, a second study $(15,16)$ indicated improvements in negative symptoms at 12 and 24 months. These comprehensive packages are promising but involve relatively long interventions and call for a broad range of therapeutic techniques. Except SST, very few interventions are provided as group therapy. Group interventions are particularly important since they are more commonly used in community psychiatry settings, where most patients receive treatment services.

\section{Experimental Objectives}

Recent literature has distinguished the negative symptoms associated with a diminished capacity to experience (apathy, anhedonia) from those who were associated with a limited capacity for expression (emotional blunting, alogia) (17-20). The apathy-anhedonia syndrome tends to be associated with a poorer prognosis than the symptoms related to diminished expression, suggesting that it is the more severe facet of the psychopathology (19). This syndrome is also related to the duration of the untreated psychosis, family history of schizophrenia, and the patient's employment status during first-episode schizophrenia (21). The distinction between diminished experience and limited expression syndromes allows more specific approaches to these problems.

A symptom-specific strategy has been used in the development of specific therapeutic techniques for positive symptoms $(22,23)$ and led to the development of more effective interventions, such as CBT for delusions or hallucinations (24). More recently, metacognitive training (MCT), which targets associated specific cognitive biases with psychosis, has appeared effective in reducing positive symptoms (25-27). A similar strategy appears to be a good way to develop psychological interventions for negative symptoms. Recent research has also shown that more specific symptom or syndrome approaches enabled a better identification of specific psychological mechanisms. For example, the endorsement of beliefs regarding low expectations of success, and perceptions of limited personal resources, are robustly associated with negative symptoms of diminished experience (anhedonia, avolition, asociality), but are not associated with negative symptoms of diminished expressivity (flattened affect, alogia). Similarly, defeatist performance beliefs are slightly related to diminished experience, but not at all related to diminished expression (28). An impaired ability to envision the future is associated with apathy (29). These results suggest that within the syndrome of diminished capacity to experience, apathy and anhedonia may be the results of the same underlying process: that is, a diminished capacity to anticipate a particular experience or the achievement of a pleasurable goal (18), or a motivational impairment (30). This article presents a new method. It is hoped that it will open new avenues of experimental investigation for interventions to improve the diminished expression syndrome in schizophrenia. The intervention is called the positive emotions program for schizophrenia (PEPS). It comprises a program of 8 1-h sessions applied to groups of 5-10 participants. The results concerning the participants have been published elsewhere (31). This paper presents the development of the program before the pilot study with participants.

\section{METHODS VALIDATION}

\section{Identification of the Component of PEPS}

Anhedonia has been defined as a reduction in the ability to experience pleasure. Despite its clinical significance, research into anhedonia has produced a paradoxical set of findings, raising 
questions about its nature. On the one hand, using self-reported measures of trait social and physical anhedonia, individuals with schizophrenia typically report experiencing lower levels of pleasure in their daily lives than non-patients (32-35). On the other hand, in laboratory studies using emotionally evocative stimuli, individuals with schizophrenia have repeatedly reported experiencing levels of pleasant emotions similar to, or even stronger than control subjects (36-38). Germans and Kring (39) resolved this inconsistency by suggesting that patients do not anticipate that pleasurable activities will indeed be pleasurable, even though they experience pleasant emotions when presented with pleasurable stimuli. This explanation is founded on the distinction between appetitive/anticipatory pleasure (i.e., anticipating the potential pleasure of taking part in a future activity) and consummatory pleasure (i.e., the actual level of pleasure experienced directly from participating in an activity). Anticipatory pleasure is linked to motivational processes that stimulate goal-directed behaviors, whereas consummatory pleasure is associated with satiety. The Temporal Experience of Pleasure Scale (TEPS) is a trait measure of pleasure (40) that distinguishes between "momentary pleasure" and "anticipation of future pleasant activities." A TEPS score study, comparing subjects with schizophrenia to controls, indicated that patients did not differ from controls on the consummatory scale; however, they reported significantly less anticipatory pleasure than controls (41). These results were replicated by the French version of TEPS (42). Bringing out this new way of conceptualizing anhedonia in schizophrenia permits a redefinition and calibration of the symptom complex as a target for treatment. If patients with schizophrenia show a deficit in their ability to anticipate pleasure, rather than experience pleasure, then cognitive training might well help these individuals anticipate pleasure from foreseeable, future activities. Ideally, treatment would lead to a greater ability to anticipate pleasure, and this, in turn, would lead to a meaningful increase in spontaneous daily activities. These considerations led us to explore the potential for an intervention that would train patients who complained of anhedonia, or a lack of desire to engage in activities, in the cognitive skills needed to increase their anticipatory pleasure (43). This first, exploratory pilot study included five participants with schizophrenia, presenting severe anhedonia, and stabilized on atypical antipsychotic medication. They received $10-25 \mathrm{~h}$ of training in anticipatory pleasure. Results showed that the patients improved on the anticipatory scale of TEPS. The patients' daily activities were also increased according to a time budget. These preliminary data were, of course, interpreted with caution, given the small study sample, but they seemed to show a promising path toward the development of new interventions to alleviate anhedonia in schizophrenia.

Further emotional deficits may be present in schizophrenia (44) and should be taken into account in the development of new interventions $(45,46)$. Strauss $(46)$ suggested maximizing positive emotional experiences by using techniques developed in the field of affective science $(47,48)$ to increase the frequency and duration of positive emotional experiences. Five techniques have been found to specifically and reliably increase the frequency, intensity, and duration of positive emotions, including anticipating the enjoyment. The others were behavioral display (expressing emotions via non-verbal behaviors), being "in the moment" (directing controlled attention toward positive experiences when they occur-savoring), communicating and celebrating positive experiences with others, and recalling previously pleasurable events. Patients reported lower levels of pleasure in savoring past, present, and future events than did normal controls, and stated that they had low expectations of their self-efficacy (49). Individuals with schizophrenia also manifested a lesser ability to maintain positive emotions (50-52). Even though observable, outward signs of emotional expression were lessened in schizophrenia, studies indicated that sufferers continued to display very subtle facial muscle movements (as measured by electromyogram) similar to, and in accordance with, their responses (53). Finally, to the best of our knowledge, it appears that communicating and celebrating positive events with others has not been studied in schizophrenia patients. However, one study showed that impaired perspective-taking - a component of cognitive empathy - was associated with functional capacity and community functioning, even after taking into account the influences of neurocognitive deficits and psychopathology (54).

With this as a background, Jérôme Favrod and Alexandra Nguyen conceived an intervention, which they named the "positive emotions program for schizophrenia," to reduce anhedonia and apathy. The program teaches skills to help overcome defeatist thinking $(55,56)$ and to increase the anticipation and maintenance of positive emotions $(44,45)$. PEPS involves eight 1 -h group sessions, administered using visual and audio materials as part of a PowerPoint presentation of slides projected onto a screen.

\section{Beta-Testing Procedure}

During its development, PEPS, as well as the sensitivity of selfreporting instruments, was beta-tested on volunteer health-care professionals in order to improve its efficacy on anticipatory and consummatory pleasure, as well as savoring. Four 1-day training sessions of $7 \mathrm{~h}$ of PEPS were beta-tested on four different mixed groups of health-care professionals. At the end of each session, oral feedback and advice were collected, as were pre- and posttest assessments. Sessions 1-3 were conducted between February and March 2014 using version 1.0 of PEPS. Session 4 was conducted in March 2015 using the improved version 1.1 of PEPS, developed on the basis of the results of the previous sessions.

\section{Participants}

Participants were health-care professionals, including psychiatrists, psychologists, nurses, occupational therapists, and social workers, interested in participating in the program's development. No participant followed more than one session. Participation was anonymous, and the subjects gave only their sex and age. The clinical studies with PEPS have the agreement of the Vaud Cantonal Ethics Commission on Human Research (127/14 and 446/15).

\section{Instruments}

The following measurement instruments were used:

- The Savoring Belief Inventory (SBI) is a self-reported scale for measuring beliefs about one's capacity for savoring things. The scale has 24 items, including a positive scale (12 items) and 
a negative scale (12 items). The inventory has good validity and a high test-re-test reliability (57). It measures a person's thinking regarding their capacity to savor positive experiences in terms of past experiences, current experiences, and future anticipation. The total SBI score is used.

- The TEPS contains 18 items included in two subscales: anticipatory pleasure (10 items) and consummatory pleasure ( 8 items) (58). Items targeting anticipatory pleasure reflect the pleasure felt when anticipating a positive or pleasant stimulus. Items measuring consummatory pleasure refer to the direct and immediate pleasure experienced upon exposure to a stimulus. Items can be general or specific. Responses to items fall on a six-point Likert scale from 1 (very false for me) to 6 (very true for me). This scale has been validated in French (42). The total anticipatory and consummatory scores of TEPS are used.

- The Anticipatory and Consummatory Interpersonal Pleasure Scale (ACIPS) $(59,60)$ is designed to assess one's ability to experience pleasure in the interpersonal domain. It is a 17-item self-reported questionnaire consisting of 7 anticipatory and 10 consummatory items. ACIPS is scored on a six-point Likert scale, ranging from 1 (very false for me) to 6 (very true for me). The format is therefore quite similar to that of TEPS. The difference between the two scales lies mainly in terms of the items' content. TEPS focuses on personal pleasure and ACIPS on interpersonal pleasure. The total anticipatory and consummatory scores of ACIPS are used.

\section{Data Analysis}

Two-tailed paired sample $t$-tests of pre- and posttest results were calculated using IBM SPSS Statistics Version 22. Cohen's $d$ effect sizes were calculated for within-subjects in correcting for dependence among means. Formula 8 from Morris and DeShon (61) was also used.

\section{RESULTS}

\section{Results of the Beta Tests}

Table 1 shows that, in session 1, the 21 participants improved on their scores significantly and clinically on the anticipatory and consummatory scales of TEPS, but not on ACIPS. Session 2 tested
PEPS using the SBI scale, and scores improved clinically and significantly for the 16 participants. Session 3 replicated the previous results of ACIPS and the SBI with 27 participants. Since version 1.0 did not improve interpersonal pleasure scores as measured by ACIPS, version 1.1 was upgraded to put more emphasis on this factor. Version 1.1 includes meditations focusing on caring for others and exercises involving interpersonal pleasure. Version 1.1 was beta-tested in session 4 . The 28 participants in session 4 improved their scores for both TEPS and ACIPS. No adverse effects were observed or reported during the four sessions with a total 92 different participants.

\section{Detailed Description of the Final Version of PEPS}

The pedagogical concept underpinning PEPS was designed according to Kolb and Kolb's model (62) of experiential learning. This model sees the learning process as the transformation of an experience into personal knowledge. The sequential organization of the learning activity starts with the learner experiencing something (the concrete experience phase). This is followed by a stage of distancing oneself from the experience through a period of observation and reflection that seeks to give the experience meaning (the reflective observation phase). Distancing oneself from the experience broadens the learner's understanding, generalizing, and developing concepts through more abstract thought (the abstract conceptualization phase). The learner then initiates an experimental approach to validate the newly acquired knowledge through reality tests (the active experimentation phase). This model's major contribution is its dynamic conception of learning, seen as "a process, not in terms of results" (63). The model claims to provide a supportive environment for all learners since it is based on adults' different learning strategies and styles, all of which can be activated through the four phases. Therefore, Kolb's model is relevant to a therapeutic program insofar as its design corresponds to a sequential logic - alternating phases of experience and reflection. The logo at the top-left of the each slide is a reminder to group leaders as to which phase the session is in.

The program uses a collaborative, egalitarian approach. Group facilitators participate in sessions just as the participants do, by doing the exercises, sharing their experiences, and carrying out

TABLE 1 | Results of the field tests with health-care professionals.

\begin{tabular}{|c|c|c|c|c|c|c|c|c|c|c|c|}
\hline Session & $N$ & Age (SD) & Sex $F / M$ & Scales & Pretest (SD) & Posttest (SD) & $r$ & $t$ & df & Two-tailed $p$ & Cohen's $d$ \\
\hline \multirow[t]{4}{*}{1} & 21 & $32.4(8.3)$ & $17 / 4$ & TEPS anticipatory & $45.8(7.1)$ & $48.3(6.8)$ & 0.86 & -3.2 & 20 & 0.005 & -0.68 \\
\hline & & & & TEPS consummatory & $38.4(4.8)$ & $40.4(4.8)$ & 0.82 & -3.1 & 20 & 0.006 & -0.69 \\
\hline & & & & ACIPS anticipatory & $31.4(3.6)$ & $31.8(4.3)$ & 0.86 & -0.9 & 20 & 0.37 & -0.19 \\
\hline & & & & ACIPS consummatory & $51.9(5.7)$ & $51.7(5.8)$ & 0.87 & 0.3 & 20 & 0.71 & -0.07 \\
\hline 2 & 16 & $36.3(8.6)$ & $9 / 7$ & SBI total & $41.4(15.5)$ & $47.3(13.0)$ & 0.93 & -4.0 & 15 & 0.001 & -1.12 \\
\hline \multirow[t]{3}{*}{3} & 27 & $38.0(11.2)$ & $21 / 6$ & ACIPS anticipatory & $32.4(3.5)$ & $32.0(6.8)$ & 0.28 & 0.3 & 26 & 0.73 & 0.07 \\
\hline & & & & ACIPS consummatory & $52.7(5.3)$ & $51.9(11.5)$ & 0.48 & 0.4 & 26 & 0.69 & 0.09 \\
\hline & & & & SBI total & $36.0(18.1)$ & $46.0(17.7)$ & 0.82 & -4.1 & 26 & $<0.001$ & -0.93 \\
\hline \multirow[t]{4}{*}{4} & 28 & 36.5 (10.9) & $23 / 5$ & TEPS anticipatory & $42.8(8.1)$ & $46.8(5.5)$ & 0.77 & -4.2 & 27 & $<0.001$ & -0.90 \\
\hline & & & & TEPS consummatory & $38.8(6.6)$ & $40.9(6.4)$ & 0.78 & -4.0 & 27 & $<0.001$ & -0.49 \\
\hline & & & & ACIPS anticipatory & $31.6(4.9)$ & $33.0(5.2)$ & 0.78 & -2.3 & 27 & 0.03 & -0.42 \\
\hline & & & & ACIPS consummatory & $49.4(8.0)$ & $52.8(5.2)$ & 0.91 & -3.5 & 27 & 0.002 & -0.30 \\
\hline
\end{tabular}

TEPS, Temporal Experience of Pleasure Scale; SBI, Savoring Belief Inventory; ACIPS, Anticipatory and Consummatory Interpersonal Pleasure Scale. 
the given tasks. Group facilitators receive a day's training before leading a group themselves and are supervised during two 1-h periods during the program.

Each session includes a number of the following steps. Part 1 begins with a welcome, followed by a 5-min relaxation-meditation exercise. In part 2, group leaders go over the homework task given during the previous session. Part 3 involves an exercise in challenging specific defeatist thoughts, which are presented using the program's two fictitious heroes - Jill and Jack. Jill, for example, expresses such defeatist thinking as "I can't relax; I'm useless." The participant's role is to challenge her belief, initially by assigning different reasons to why Jill has difficulty relaxing. They learn to find reasons that might be linked not only to the program's heroine but also to other people or her environment. They subsequently try to develop an alternative, more positive way of thinking.

The following slides show how the exercise appears to the participants. This first slide presents a defeatist belief.

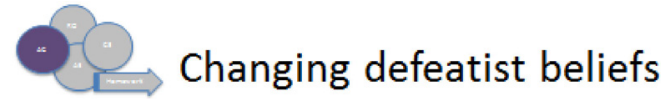

- Jill encountered a problem during the relaxation exercise.

- She says that she just can't relax and it's useless trying.

- Our job is to help her find other reasons to explain why she can't relax.

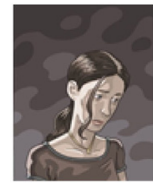

The next slide presents questions to find a more balanced set of reasons to explain Jill's belief that she is unable to relax. Since defeatist beliefs are often linked to the internal attribution of failures, participants are asked to find a set of different reasons to explain why Jill was not able to relax. These questions are asked by the group leaders to the participants. Each of the eight sessions of PEPS will address a defeatist belief using the same methods in order to facilitate patients' understanding of how the method works.

\section{"I can't relax and it's useless trying."}

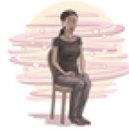

Help Jill to develop a more balanced set of reasons as to why she cannot relax.

- What reasons might be linked to her?

- What reasons might be linked to the people around her?

- What reasons might be linked to her environment?

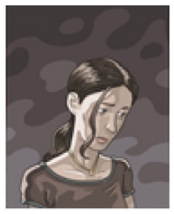

The third slide only appears after the participants have given answers to slide 2. Other suggestions are also given to complement or confirm the work they did for the previous slide.

\section{"I can't relax and it's useless trying."}

Help Jill to develop a more balanced set of reaso

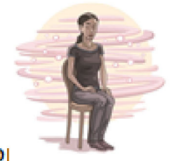
why she cannot relax.

- What reasons might be linked to her? "I find it hard to relax. I can't concentrate on one thing. I' $m$ too stressed."

- What reasons might be linked to the people around her?

"The group leaders expect far too much of me, and their instructions are never clear. I can't relax with so many people around me. I don't like the voice used on the relaxation recording."

- What reasons might be linked to her environment? "There is too much noise in the room."

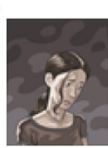

The fourth slide asks the participants to give an alternative to Jill's conclusion and defeatist belief that she is useless.

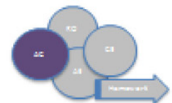

\section{"Am I really useless?"}

- What alternative statements could Jill use?

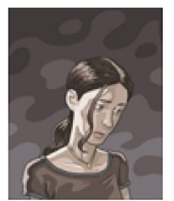

The final slide in this sequence about changing defeatist beliefs gives suggestions to complement or confirm the work the participants did for the previous slide.

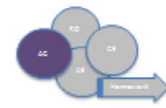

\section{"Am I really useless?"}

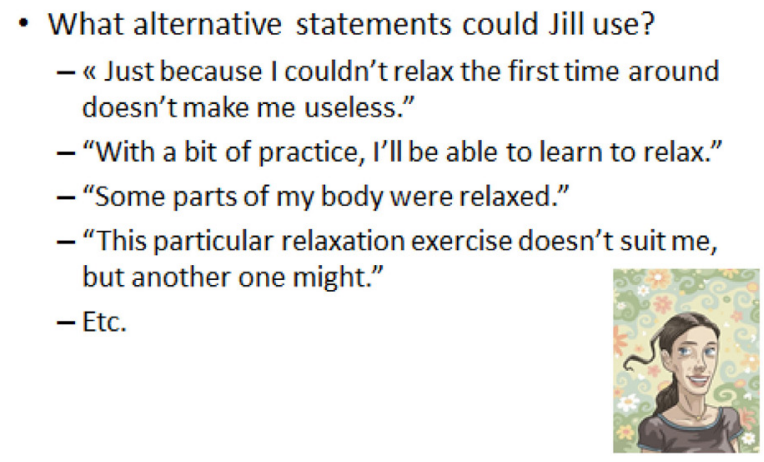

Subsequently, and according to the session's theme, participants learn and practice a new skill to improve their anticipation or maintenance of pleasure. The session ends with group leaders setting the homework task that the participants must accomplish for the next session. 
The skills taught include savoring a pleasant experience, expressing emotions by increasing behavioral expression, making the most of or capitalizing on positive moments, and anticipating pleasant moments in the future. Savoring a pleasant experience involves becoming aware of that pleasure or of the positive emotions the participant feels at a given moment (47). For example, participants are asked to look at a picture of pleasant countryside or listen to soothing music, and hence become aware of the pleasurable experience of doing this and thus appreciate it. Increasing behavioral expression of emotions involves using facial expressions or gestures to accompany that positive emotion. The participants are asked to imitate pictures of actors expressing a positive emotion and to become aware of the sensations this produces. The next slide introduces the exercise.

\section{$\because$ Behavioral expression}

- You'll see images of faces expressing a pleasant feeling.

- With each successive picture, imagine that person is you. Imitate their facial expressions.

- Be aware of how your body feels when you express yourself about the pleasant feeling.

The next slide is an example of a picture to imitate.

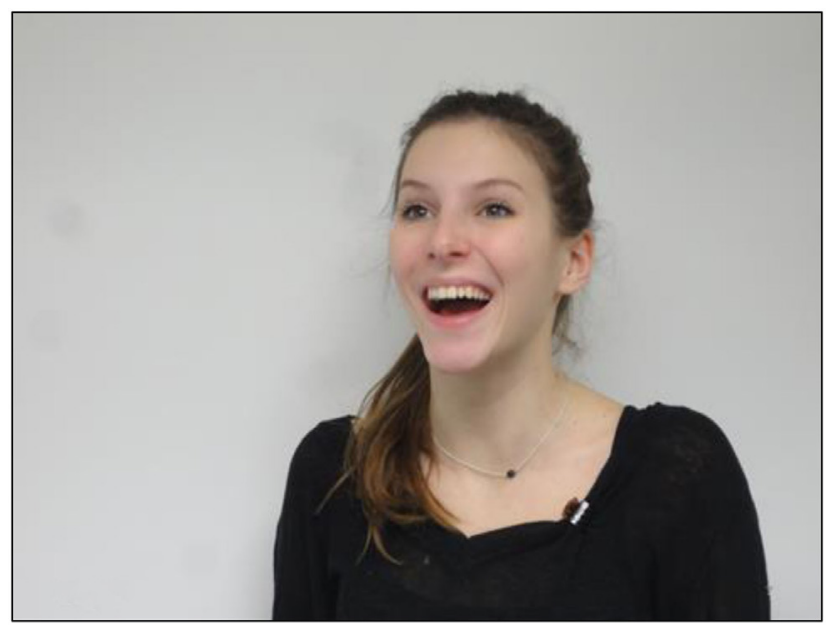

The following slide allows participants to think about the exercise. Group leaders will help each participant to share their feelings during the exercise. The group leaders will also describe what they have felt, in order to help demonstrate ways of sharing experiences and guide participants in self-observation.

\section{What did you feel?}

\section{- How did you feel after copying these facial expressions?}

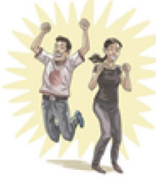

Making the most of positive moments entails communicating and celebrating positive events with others. For example, participants are asked to describe positive events to one another through role playing. The next slides show a complete sequence of training with its experiential learning steps: concrete experience, reflective observation, abstract conceptualization, and active experimentation. During the concrete experience phase, participants experience the skill they are to be taught. During reflective observation phase, they consciously express and formulate the ingredients of that experience. During abstract conceptualization phase, the participants receive theoretical information about the skill they are being taught. Finally, during active experimentation phase, they practice the skill in their natural environment as homework. The homework is reviewed at the beginning of the next session.

\section{- Making the most of an enjoyable event}

- Think of an enjoyable event and describe it to your neighbor in the group.

- "You'll never believe what happened to me. Well, I was ..."

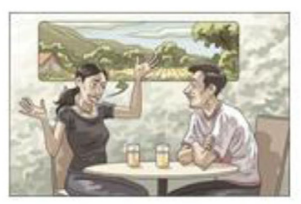

\section{How did you feel as you described your enjoyable event?}

- Describe your feelings and listen to what your role-playing partner says about his/her feelings.

- How do you feel after this role-playing exercise? 


\section{Making the most of an enjoyable event}

- Celebrating and communicating a positive event with others improves your mood beyond the positive impact of the event itself.

- It even improves your immune response.

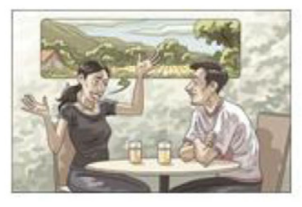

\section{Before the next session}

- Let's practice making the most of positive events.

- Let's tell our friends about positive events.

- Let's observe the effects that sharing this positive event has on us and our friends.

Anticipating pleasant moments involves imagining the sensations produced by positive future events. This strategy is meant to guide the participants through different positive feelings and emotions. It can engage their senses, for example, by imagining they are eating a smooth, shiny, crunchy, tasty, sweet-smelling fruit, or by anticipating the emotion produced and the physical sensations experienced upon the completion of a pleasurable physical or social activity. A simple homework task is assigned to be done between each session. For example, this could be choosing an image or an object that provokes a positive emotion or feeling in the participant, who must then bring it back and describe it to the group. The original French version of PEPS can be downloaded for free at http://www.seretablir.net/outils-interventions/peps/.

\section{DISCUSSION}

\section{Key Findings}

Drug and psychological treatments for the negative symptoms of schizophrenia have shown poor clinical efficacy. Furthermore, they require lengthy therapeutic interventions involving highly skilled professionals. This paper presents a specific, short, easy to use, group-based intervention to improve pleasure, and motivation in schizophrenia. A more targeted syndrome approach was grafted to a model of the advancement of psychological therapies for delusions. The program targets apathy and anhedonia as they can be combined into a single reduced-experience syndrome. The program was built with regard to the specific deficits described in the literature on pleasure and motivation. The program was developed by beta-testing on health-care professionals and was improved according to the results of earlier tests. A pilot study was conducted with participants who met the ICD-10 criteria for schizophrenia or schizoaffective disorders (31). Thirty-one participants completed the program; those who dropped out did not differ significantly from completers. Participation in the program was accompanied by statistically significant reductions in the total scores for avolition-apathy and anhedonia-asociality on the Scale for the Assessment of Negative Symptoms, with moderate effect sizes. Furthermore, there was a statistically significant reduction of depression on the CDSS, with a large effect size. Emotional blunting and alogia remained stable during the intervention. The original program in French can be downloaded for free on the Internet. It was designed to be easy to use and applicable in group sessions so as to meet the needs of community care psychiatry.

\section{Potential Shortcomings and Limitations}

Positive emotions program for schizophrenia was designed using a recovery-oriented approach rather than a deficit-centered approach. The deficits of pleasure, and above all of motivation, may be related to factors that were not selected as targets in the program. This could be mainly because the authors were looking for a rapid, targeted intervention on the diminished experience syndrome. For example, apathy is associated with poor performance on executive tests (64-66). CR has been shown to improve executive functioning, but although CR yields lasting effects on global cognition and functioning, its influence on symptom effects is small and disappears over time (67). However, a recent study indicated that anticipation abnormalities are associated rather to negative beliefs about potentially rewarding social situations than neurocognitive deficits (68). Motivation may also be affected by medication; for example, the D2 antagonistic effect of antipsychotic agents reduces anticipation of a monetary reward (69). PEPS does not include medication in its intervention.

The use of health-care professionals in the beta tests for developing the program may be questionable since they were not representative groups of people with schizophrenia. The high female-to-male ratio of the beta test samples did not fit with the high male-to-female ratio of patients with enduring schizophrenia (70). However, these professionals were easy to reach out to, familiar with the problems surrounding schizophrenia, and able to give knowledgeable feedback on PEPS exercises. However, this familiarity with schizophrenia may also be a bias against innovation. The developers were well aware of these risks. The main reasons for the beta tests were to quickly evaluate the intervention's feasibility, its impact on the self-reporting scales selected, and the program's safety before the clinical phase in the development of PEPS.

\section{Future Directions}

The findings presented here indicate that PEPS is indeed a feasible intervention, and it was associated with an apparently specific reduction of anhedonia and apathy. However, these findings are limited by the absence of a control group and the fact that the rater was not blind to the treatment objectives. A randomized controlled study with blind raters is needed to assess more correctly the efficacy of PEPS. 


\section{AUTHOR CONTRIBUTIONS}

AN and JF, in equal measure, conceptualized this research and PEPS, acquired, analyzed, and interpreted the data, and drafted the first version of the manuscript. LF, IM, PG, and CB gave a substantial contribution to the analysis and interpretation of data and critically revised the article for important intellectual content. All the authors approved the final version for publication. All the authors agree to be accountable for all aspects of the work by ensuring that any questions related to its accuracy or integrity can be appropriately investigated and resolved.

\section{REFERENCES}

1. Foussias G, Agid O, Fervaha G, Remington G. Negative symptoms of schizophrenia: clinical features, relevance to real world functioning and specificity versus other CNS disorders. Eur Neuropsychopharmacol (2014) 24:693-709. doi:10.1016/j.euroneuro.2013.10.017

2. Tsang HW, Leung AY, Chung RC, Bell M, Cheung WM. Review on vocational predictors: a systematic review of predictors of vocational outcomes among individuals with schizophrenia: an update since 1998. Aust N Z J Psychiatry (2010) 44:495-504. doi:10.3109/00048671003785716

3. Marder SR. Clinician perceptions, expectations, and management of negative symptoms in schizophrenia. J Clin Psychiatry (2013) 74:e01. doi:10.4088/ JCP.12045tx4c

4. Ventura J, Wood RC, Hellemann GS. Symptom domains and neurocognitive functioning can help differentiate social cognitive processes in schizophrenia: a meta-analysis. Schizophr Bull (2013) 39:102-11. doi:10.1093/schbul/sbr067

5. Fervaha G, Foussias G, Agid O, Remington G. Impact of primary negative symptoms on functional outcomes in schizophrenia. Eur Psychiatry (2014) 29:449-55. doi:10.1016/j.eurpsy.2014.01.007

6. Moller HJ. Clinical evaluation of negative symptoms in schizophrenia. Eur Psychiatry (2007) 22:380-6. doi:10.1016/j.eurpsy.2007.03.010

7. Erhart SM, Marder SR, Carpenter WT. Treatment of schizophrenia negative symptoms: future prospects. Schizophr Bull (2006) 32:234-7. doi:10.1093/ schbul/sbj055

8. Turkington D, Morrison AP. Cognitive therapy for negative symptoms of schizophrenia. Arch Gen Psychiatry (2012) 69:119-20. doi:10.1001/ archgenpsychiatry.2011.141

9. Fusar-Poli P, Papanastasiou E, Stahl D, Rocchetti M, Carpenter W, Shergill S, et al. Treatments of negative symptoms in schizophrenia: meta-analysis of 168 randomized placebo-controlled trials. Schizophr Bull (2015) 41(4):892-9. doi:10.1093/schbul/sbu170

10. Elis O, Caponigro JM, Kring AM. Psychosocial treatments for negative symptoms in schizophrenia: current practices and future directions. Clin Psychol Rev (2013) 33:914-28. doi:10.1016/j.cpr.2013.07.001

11. Eack SM, Greenwald DP, Hogarty SS, Cooley SJ, Dibarry AL, Montrose DM, et al. Cognitive enhancement therapy for early-course schizophrenia: effects of a two-year randomized controlled trial. Psychiatr Serv (2009) 60:1468-76. doi:10.1176/appi.ps.60.11.1468

12. Eack SM, Mesholam-Gately RI, Greenwald DP, Hogarty SS, Keshavan MS. Negative symptom improvement during cognitive rehabilitation: results from a 2-year trial of cognitive enhancement therapy. Psychiatry Res (2013) 209:21-6. doi:10.1016/j.psychres.2013.03.020

13. Farreny A, Aguado J, Ochoa S, Huerta-Ramos E, Marsa F, Lopez-Carrilero $\mathrm{R}$, et al. REPYFLEC cognitive remediation group training in schizophrenia: looking for an integrative approach. Schizophr Res (2012) 142:137-44. doi:10.1016/j.schres.2012.08.035

14. Hogarty GE, Greenwald D, Ulrich RF, Kornblith SJ, Dibarry AL, Cooley S, et al. Three-year trials of personal therapy among schizophrenic patients living with or independent of family, II: effects on adjustment of patients. Am J Psychiatry (1997) 154:1514-24. doi:10.1176/ajp.154.11.1514

15. Petersen L, Jeppesen P, Thorup A, Abel MB, Ohlenschlaeger J, Christensen TO, et al. A randomised multicentre trial of integrated versus standard

\section{ACKNOWLEDGMENTS}

Sébastien Perroud, known as PET, drew the cartoons; Charlotte Aeschbacher and Yael Horowicz were the models for the photographs depicting positive emotions.

\section{FUNDING}

This work was supported by a donation from Dr. Alexander Engelhorn and Swiss National Science Foundation grant number 105319_163355/1.

treatment for patients with a first episode of psychotic illness. BMJ (2005) 331:602. doi:10.1136/bmj.38565.415000.E01

16. Thorup A, Petersen L, Jeppesen P, Ohlenschlaeger J, Christensen T, Krarup G, et al. Integrated treatment ameliorates negative symptoms in first episode psychosis - results from the Danish OPUS trial. Schizophr Res (2005) 79:95-105. doi:10.1016/j.schres.2004.12.020

17. Blanchard JJ, Cohen AS. The structure of negative symptoms within schizophrenia: implications for assessment. Schizophr Bull (2006) 32:238-45 doi:10.1093/schbul/sbj013

18. Foussias G, Remington G. Negative symptoms in schizophrenia: avolition and Occam's razor. Schizophr Bull (2010) 36:359-69. doi:10.1093/schbul/ sbn094

19. Strauss GP, Horan WP, Kirkpatrick B, Fischer BA, Keller WR, Miski P, et al. Deconstructing negative symptoms of schizophrenia: avolition-apathy and diminished expression clusters predict clinical presentation and functional outcome. J Psychiatr Res (2013) 47:783-90. doi:10.1016/j. jpsychires.2013.01.015

20. Hartmann MN, Hager OM, Reimann AV, Chumbley JR, Kirschner M, Seifritz $\mathrm{E}$, et al. Apathy but not diminished expression in schizophrenia is associated with discounting of monetary rewards by physical effort. Schizophr Bull (2015) 41:503-12. doi:10.1093/schbul/sbu102

21. Ergul C, Ucok A. Negative symptom subgroups have different effects on the clinical course of schizophrenia after the first episode: a 24-month follow up study. Eur Psychiatry (2015) 30:14-9. doi:10.1016/j.eurpsy.2014.07.005

22. Chadwick P, Birchwood M, Trower P. Cognitive Therapy for Delusions, Voices and Paranoia. Chichester: John Wiley \& Sons Ltd (1996).

23. Favrod J, Vianin P, Pomini V, Mast FW. A first step toward cognitive remediation of voices: a case study. Cogn Behav Ther (2006) 35:159-63. doi:10.1080/16506070600802993

24. Zimmermann G, Favrod J, Trieu VH, Pomini V. The effect of cognitive behavioral treatment on the positive symptoms of schizophrenia spectrum disorders: a meta-analysis. Schizophr Res (2005) 77:1-9. doi:10.1016/j. schres.2005.02.018

25. Favrod J, Rexhaj S, Bardy S, Ferrari P, Hayoz C, Moritz S, et al. Sustained antipsychotic effect of metacognitive training in psychosis: a randomized-controlled study. Eur Psychiatry (2014) 29:275-81. doi:10.1016/j.eurpsy.2013.08.003

26. Kumar D, Menon M, Moritz S, Woodward TS. Using the back door: metacognitive training for psychosis. Psychosis (2015) 7:166-178. doi:10.1080/17 522439.2014.913073

27. Moritz S, Veckenstedt R, Andreou C, Bohn F, Hottenrott B, Leighton L, et al. Sustained and "sleeper" effects of group metacognitive training for schizophrenia: a randomized clinical trial. JAMA Psychiatry (2014) 71:1103-11. doi:10.1001/jamapsychiatry.2014.1038

28. Couture SM, Blanchard JJ, Bennett ME. Negative expectancy appraisals and defeatist performance beliefs and negative symptoms of schizophrenia Psychiatry Res (2011) 189:43-8. doi:10.1016/j.psychres.2011.05.032

29. Raffard S, Esposito F, Boulenger JP, Van Der Linden M. Impaired ability to imagine future pleasant events is associated with apathy in schizophrenia. Psychiatry Res (2013) 209:393-400. doi:10.1016/j.psychres.2013.04.016

30. Strauss GP, Morra LF, Sullivan SK, Gold JM. The role of low cognitive effort and negative symptoms in neuropsychological impairment in schizophrenia. Neuropsychology (2015) 29:282-91. doi:10.1037/neu0000113 
31. Favrod J, Nguyen A, Fankhauser C, Ismailaj A, Hasler JD, Ringuet A, et al. Positive emotions program for schizophrenia (PEPS): a pilot intervention to reduce anhedonia and apathy. BMC Psychiatry (2015) 15:231. doi:10.1186/ s12888-015-0610-y

32. Blanchard JJ, Horan WP, Brown SA. Diagnostic differences in social anhedonia: a longitudinal study of schizophrenia and major depressive disorder. J Abnorm Psychol (2001) 110:363-71. doi:10.1037/0021-843X.110.3.363

33. Herbener ES, Harrow M. Are negative symptoms associated with functioning deficits in both schizophrenia and nonschizophrenia patients? A 10-year longitudinal analysis. Schizophr Bull (2004) 30:813-25. doi:10.1093/oxfordjournals.schbul.a007134

34. Harrow M, Grossman LS, Jobe TH, Herbener ES. Do patients with schizophrenia ever show periods of recovery? A 15-year multi-follow-up study. Schizophr Bull (2005) 31:723-34. doi:10.1093/schbul/sbi026

35. Herbener ES, Harrow M, Hill SK. Change in the relationship between anhedonia and functional deficits over a 20-year period in individuals with schizophrenia. Schizophr Res (2005) 75:97-105. doi:10.1016/j. schres.2004.12.013

36. Kring AM. Emotion in schizohrenia: old mystery, new understanding. Curr Dir Psychol Sci (1999) 8:160-3. doi:10.1111/1467-8721.00038

37. Kring AM, Earnst KS. Stability of emotional responding in schizophrenia. Behav Ther (1999) 30:373-88. doi:10.1016/S0005-7894(99)80016-1

38. Gold JM, Waltz JA, Prentice KJ, Morris SE, Heerey EA. Reward processing in schizophrenia: a deficit in the representation of value. Schizophr Bull (2008) 34:835-47. doi:10.1093/schbul/sbn068

39. Germans MK, Kring AM. Hedonic deficit in anhedonia: support for the role of approach motivation. Pers Individ Dif (2000) 28:659-72. doi:10.1016/ S0191-8869(99)00129-4

40. Gard DE, Germans Gard M, Kring AM, John OP. Anticipatory and consummatory components of the experience of pleasure: a scale development study. J Res Pers (2006) 40:1086-102. doi:10.1016/j.jrp.2005.11.001

41. Gard DE, Kring AM, Gard MG, Horan WP, Green MF. Anhedonia in schizophrenia: distinctions between anticipatory and consummatory pleasure. Schizophr Res (2007) 93(1-3):253-60. doi:10.1016/j.schres.2007.03.008

42. Favrod J, Ernst F, Giuliani F, Bonsack C. Validation francaise de lechelle d'experience temporelle du plaisir. Encephale (2009) 35:241-8. doi:10.1016/j. encep.2008.02.013

43. Favrod J, Giuliani F, Ernst F, Bonsack C. Anticipatory pleasure skills training: a new intervention to reduce anhedonia in schizophrenia. Perspect Psychiatr Care (2010) 46:171-81. doi:10.1111/j.1744-6163.2010.00255.x

44. Kring AM, Elis O. Emotion deficits in people with schizophrenia. Annu Rev Clin Psychol (2013) 9:409-33. doi:10.1146/annurev-clinpsy-050212-185538

45. Favrod J, Rexhaj S, Nguyen A, Cungi C, Bonsack C. Projecting oneself into the future, an intervention for improving pleasure in patients with anhedonia. In: Ritsner MS, editor. Anhedonia: A Comprehensive Handbook Volume I: Conceptual Issues and Neurobiological Advances. Dordrecht: Springer Science+Business Media (2014). p. 95-104.

46. Strauss GP. Translating basic emotion research into novel psychosocial interventions for anhedonia. Schizophr Bull (2013) 39:737-9. doi:10.1093/ schbul/sbt082

47. Bryant FB. The Process of Savoring: A New Model of Positive Experience. Mahwah, NJ: Lawrence Erlbaum (2007).

48. Quoidbach J, Berry EV, Hansenne M, Mikolajczak M. Positive emotion regulation and well-being: comparing the impact of eight savoring and dampening strategies. Pers Indiv Differ (2010) 49:368-73. doi:10.1016/j. paid.2010.03.048

49. Cassar R, Applegate E, Bentall RP. Poor savouring and low self-efficacy are predictors of anhedonia in patients with schizophrenia spectrum disorders. Psychiatry Res (2013) 210:830-4. doi:10.1016/j.psychres.2013.09.017

50. Horan WP, Wynn JK, Kring AM, Simons RF, Green MF. Electrophysiological correlates of emotional responding in schizophrenia. J Abnorm Psychol (2010) 119:18-30. doi:10.1037/a0017510

51. Kring AM, Germans Gard M, Gard DE. Emotion deficits in schizophrenia: timing matters. J Abnorm Psychol (2011) 120:79-87. doi:10.1037/ a0021402

52. Ursu S, Kring AM, Gard MG, Minzenberg MJ, Yoon JH, Ragland JD, et al. Prefrontal cortical deficits and impaired cognition-emotion interactions in schizophrenia. Am J Psychiatry (2011) 168:276-85. doi:10.1176/appi. ajp.2010.09081215
53. Kring AM, Moran EK. Emotional response deficits in schizophrenia: insights from affective science. Schizophr Bull (2008) 34:819-34. doi:10.1093/schbul/ sbn071

54. Smith MJ, Horan WP, Karpouzian TM, Abram SV, Cobia DJ, Csernansky JG. Self-reported empathy deficits are uniquely associated with poor functioning in schizophrenia. Schizophr Res (2012) 137:196-202. doi:10.1016/j. schres.2012.01.012

55. Rector NA. Dysfunctional attitudes and symptom expression in schizophrenia: differential associations with paranoid delusions and negative symptoms. J Cogn Psychother (2004) 18:163-73. doi:10.1891/jcop.18.2.163.65959

56. Grant PM, Beck AT. Defeatist beliefs as a mediator of cognitive impairment, negative symptoms, and functioning in schizophrenia. Schizophr Bull (2009) 35:798-806. doi:10.1093/schbul/sbn008

57. Bryant FB. Savoring beliefs inventory (SBI): a scale for measuring beliefs about savouring. J Ment Health (2003) 12:175-96. doi:10.1080/0963823031 000103489

58. Gard DE, Gard MG, Kring AM, John OP. Anticipatory and consummatory components of the experience of pleasure: a scale development study. J Res Pers (2006) 40:1086-102. doi:10.1016/j.jrp.2005.11.001

59. Gooding DC, Pflum MJ. The assessment of interpersonal pleasure: introduction of the Anticipatory and Consummatory Interpersonal Pleasure Scale (ACIPS) and preliminary findings. Psychiatry Res (2014) 215:237-43. doi:10.1016/j.psychres.2013.10.012

60. Gooding DC, Pflum MJ. Further validation of the ACIPS as a measure of social hedonic response. Psychiatry Res (2014) 215:771-7. doi:10.1016/j. psychres.2013.11.009

61. Morris SB, DeShon RP. Combining effect size estimates in meta-analysis with repeated measures and independent-groups designs. Psychol Methods (2002) 7:105-25. doi:10.1037/1082-989X.7.1.105

62. Kolb AY, Kolb DA. The learning way: meta-cognitive aspects of experiential learning. Simul Gaming (2009) 40:297-327. doi:10.1177/1046878108325713

63. Balleux A. Évolution de la notion d'apprentissage expérientiel en éducation des adultes: vingt-cinq ans de recherche. Rev Sci Edu (2000) 26:263-86. doi:10.7202/000123ar

64. Faerden A, Vaskinn A, Finset A, Agartz I, Ann Barrett E, Friis S, et al. Apathy is associated with executive functioning in first episode psychosis. BMC Psychiatry (2009) 9:1. doi:10.1186/1471-244X-9-1

65. Konstantakopoulos G, Ploumpidis D, Oulis P, Patrikelis P, Soumani A, Papadimitriou GN, et al. Apathy, cognitive deficits and functional impairment in schizophrenia. Schizophr Res (2011) 133:193-8. doi:10.1016/j. schres.2011.07.003

66. Hartmann MN, Kluge A, Kalis A, Mojzisch A, Tobler PN, Kaiser S. Apathy in schizophrenia as a deficit in the generation of options for action. J Abnorm Psychol (2015) 124(2):309-18. doi:10.1037/abn0000048

67. Wykes T, Huddy V, Cellard C, Mcgurk SR, Czobor P. A meta-analysis of cognitive remediation for schizophrenia: methodology and effect sizes. Am J Psychiatry (2011) 168:472-85. doi:10.1176/appi.ajp.2010.10060855

68. Engel M, Fritzsche A, Lincoln TM. Anticipation and experience of emotions in patients with schizophrenia and negative symptoms. An experimental study in a social context. Schizophr Res (2016) 170(1):191-7. doi:10.1016/j. schres.2015.11.028

69. Kirsch P, Ronshausen S, Mier D, Gallhofer B. The influence of antipsychotic treatment on brain reward system reactivity in schizophrenia patients. Pharmacopsychiatry (2007) 40:196-8. doi:10.1055/s-2007-984463

70. MacDonald AW, Schulz SC. What we know: findings that every theory of schizophrenia should explain. Schizophr Bull (2009) 35:493-508. doi:10.1093/ schbul/sbp017

Conflict of Interest Statement: The authors declare that this research was conducted in the absence of any commercial or financial relationships that could be construed as a potential conflict of interest.

Copyright (c) 2016 Nguyen, Frobert, McCluskey, Golay, Bonsack and Favrod. This is an open-access article distributed under the terms of the Creative Commons Attribution License (CC BY). The use, distribution or reproduction in other forums is permitted, provided the original author(s) or licensor are credited and that the original publication in this journal is cited, in accordance with accepted academic practice. No use, distribution or reproduction is permitted which does not comply with these terms. 